\title{
Supercritical water processes: future prospects
}

María José Cocero.

High Pressure Processes research group. Department of Chemical Engineering and Environmental Technology. Valladolid University. 47011 Valladolid (Spain).

mjcocero@iq.uva.es

\section{Abstracts}

This contribution examines the challenges faced by supercritical water processes for industrial development. As an alternative, the intensification of the supercritical water processes is presented in order to reduce the size of the equipment needed and to facilitate the scaling up of the process. The perspective of developing micro combustors using hydrothermal flames as the internal heat source could open up an alternative for the in-situ energy generation in biorefineries, for example. The fundamental studies about supercritical water hydrolysis using ultrafast reactors has enabled extremely high selectivity in the biomass fractionation processes, and in the production of $\mathrm{C} 2$ and $\mathrm{C} 3$ building blocks from key components. The high-energy consumption of this process is another issue that limit its commercialization. In the examples proposed, the energy, work recovery and energy integration allows the reduction of the total energy consumption and, in some processes, the availability of extra energy as heat and work.

Key Words: Process intensification, micro combustors, oxidation, hydrolysis, shaft work, energy integration.

\section{Current State}

Supercritical water (SCW) has been used as coolant in nuclear reactors for many years. In addition, geothermal studies about the water inside the earth's crust have 
contributed knowledge to the hydrothermal processes [1]. Modell had the vision to develop industrial processes based on the use of water at supercritical conditions after the preliminary studies about the total miscibility of hydrocarbons in SCW [2]. His companies Modar inc and Modell were a key point in the development of the supercritical water oxidation processes for environmental applications [3].

In its origin, the process aroused a great interest among the process industries or in public organisms as being a solution to recalcitrant waste treatment problems. Companies such as General Atomics or Foster and Wheeler were involved in the development of the supercritical water transpiring wall reactor. They made relevant contributions, working in projects for public USA organisms, to the development of injectors to achieve good mixing [4].

In Europe, Franck significantly improved the available information regarding SCW properties [5-7]. Companies such as Chematur built the first sludge SCWO pilot plant with a treatment capacity of $200 \mathrm{~kg} / \mathrm{h}$, in 1998 [8]. In Spain, the EMGRISA public company supported Valladolid University's research to develop the first cooled wall reactor in a pilot plant with a treatment capacity of $30 \mathrm{~kg} / \mathrm{h}$ in 1994, and a demonstration plant with a treatment capacity of $200 \mathrm{~kg} / \mathrm{h}$ in 2002 [9].

The main industrial development associated with sludge treatment has involved tubular reactors [10-12]. Conventional reactors are thin tubes about hundred meters long, with mixing problems that force them to work with great excesses of oxygen and with evident plugging problems due to solid precipitation. In practice, industrial plants work with two reactors, one under operation and the other undertaking the cleaning of deposited solids [13-15]. In some applications, the changeover of the reactors takes over 30 minutes. Furthermore, cleaning is a highly energy- and time-consuming step. Its industrial development has not progressed due to the lack of control of corrosion and salt precipitation processes, the high reactor surface exposed to corrosion and the 
small diameter that favors plugging problems, in addition to the high processing cost [16-18].

A well-known problem of SCW oxidation is the energy requirement, which can be very high, particularly, if simple plug-flow tubular reactors are used, inasmuch as these designs require the preheating of the influent up to supercritical water temperature. The correct use of the energy produced by the oxidation is a crucial step in order to make SCWO processes economically viable [19-21].

SCW gasification is another technology to which important research efforts have been devoted, but it has not been possible to progress. Only one demonstration industrial scale plant Hydromethans AG is in Switzerland [22]. Kruse concluded in a recent review that the main reason why a SCW gasification process is not attractive for industry today is due to the high processing costs [23]. Only biomass with high disposal costs are considered to be interesting feedstock, such as sewage sludge. Kruse identified the same problems found in the SCWO: plugging, corrosion, reactor design and material selection. As possible future developments, Kruse proposed hydrothermal gasification as part of a bio-refinery. During hydrothermal liquefaction, a tarry oil and an aqueous phase are produced. So, It was then proposed to gasify the organic compounds in the aqueous effluent, and use the hydrogen to up-grade the oil [23-25].

More recently, material synthesis in SCW is a technology which is approaching the market. Adschiri has produced different materials for new industrial developments [26]. Lee had a demonstration plant under operation which synthesized nanoparticles by using SCW [27]. In recent years, Lester has coordinated the Shyman EU project for the development of a 1000 ton/year demonstration plant producing nanomaterials [28-29]. Again, this technology has not reached the industrial development that it could achieve, due to the high processing cost. In addition to the energy consumption, the effluent particle concentration is very low, and the water has to be eliminated, so the downstream processing could require a lot of both, time and energy. In the cases of 
many materials that have been developed, the cost is much higher than the same materials that are produced by conventional technologies. The opportunity, now, lies in developing new materials that can not be produced by conventional technologies, or that would be more expensive to produce conventionally.

In this special issue, Adschiri [30] and Aymonier [31] illustrate the interest of this technology for the production of advanced nanostructured materials and for developing new nanotechnology applications.

The petrochemical companies are studying the upgrading of heavy oil by SCW. This process takes advantage of the low dielectric constant of water, which allows hydrocarbons' solubility. In addition, temperature and pressure can be manipulated to adjust the water's ionic product creating a highly ionic medium, with high $[\mathrm{H}+]$ concentration that could improve the hydrolysis [32]. Although many studies have not been published, relevant manuscripts about thermodynamics, kinetics, and experimental and theoretical developments on the phase equilibria of relevant waterhydrocarbon systems are available [33-35]. The advantage of this process over other upgrading technologies is the high process intensification that can be achieved by the use of SCW.

Regarding energy production, power plants with SCW steam generators as the Benson type are conventional. [36-37]. Also novel SCW reactors are considered more efficient reactors for nuclear plants [38].

\section{SCW processes Challenges}

The strong features of the supercritical water processes lie in the knowledge of the processes fundamentals supported by the abundant research SCW. Specifically: the SCW properties and its mixtures; thermodynamic and kinetic studies; thermodynamic modelling; and the computational fluid dynamic model designed to improve the hydrodynamic reactors behavior. Operation at high temperature could mean fast reaction kinetics, which could allow extremely fast processes to be developed. 
The weak features include the high processing cost, in addition to the operational problems associated with plugging, corrosion, reactor design, dilution of the effluents, and high energy consumption. The processes have high costs, and this in turn has an important impact on the high cost of products.

From my point of view, the main challenges concerning SCW industrial implementation are:

To reduce the cost of the processes, by reducing the cost of equipment.

To reduce the operation cost by improving the heat and work recovery and the integration of the energy, to reduce the overall energy consumption.

To improve technical issues regarding operations with solids at a high temperature and pressure, pumping highly concentrated solid suspensions, minimizing the abrasion of valve stems, and improving the solid output from SCW reactors.

To implement downstream processes in order to achieve marketable products.

\section{SCW process perspectives.}

One way to reduce equipment costs is to take advantage of the SCW process's fast kinetics to reduce reaction time, which will reduce the reactor size. By reducing the residence time from 10 minutes to milliseconds, it is possible to change conventional reactor volumes of $\mathrm{m}^{3}$ for reactors with volumes of $\mathrm{dm}^{3}$. That means reducing the reactor size, thus facilitating the scale-up of the process as well as the reactor control. In some applications, it is possible to improve the reactor's design to reduce the problems associated with operations involving solids at a high pressure and temperature.

It is possible to reduce the operation cost by improving the energy and work recovery, for example, by recovering the work associated with the depressurization, and implementing energy integration [39]. 
The processes should be focused on obtaining products that are closer to the market. As there is much information about process fundamentals, the research should be oriented to develop "products close to the market". If it is the case that the process fundamentals are not yet well known, our first step is to improve our knowledge of the process fundamentals in order to achieve a faster way of developing new processes and new products.

In this section, the perspectives of the development of three supercritical water processes are presented. These processes can operate with residence times of milliseconds, which could achieve a high level of process intensification. The energy and work recovery, as well as the energy integration, are taken into account in order to minimize energy consumption or even produce net energy as heat and shaft work.

\subsection{Micro-combustors operating on the intensification of the supercritical water} oxidation process, using hydrothermal flames as the internal heat source.

In 1988, Schilling and Franck achieved the formation of a diffusion flame in homogenous supercritical aqueous fluids. The combustion of $30 \%$ methane with oxygen in the homogenous supercritical phase was investigated, and stationary diffusion flames were generated up to pressures of 2000 bar and temperatures of 500 ${ }^{\circ} \mathrm{C}[40]$. At that time this was a considered a scientific curiosity, but nowadays the effect of operation conditions on the ignition temperature has been studied in order to achieve stable mixing and diffusional hydrothermal flames [41-44].

Usually a flame is defined as the visible part of the combustion reaction and consists of a surface where reaction occurs. This surface separates the oxidant from the fuel (in the case of diffusion, non-premixed, flames) or it separates the reagents from the reaction products (in case of premixed flames). The surface moves towards the reagents with a flame front velocity. If this velocity is the same as the fluid velocity, the flame will remain stationary. If flow velocity is higher or lower than flame front velocity, the flame will be blown away from the tube or it will move against the flow, resulting in 
backfire, respectively [45]. See figure 1 for simulation contours of a hydrothermal flame.

It is possible to operate with ignition temperatures of between 400 and $500^{\circ} \mathrm{C}$, and residence times between $10-100 \mathrm{~ms}$. The flame ignition is affected by fuel, oxidant, ratio of fuel/oxidant and the geometry of the injection system [46-50], and it is possible to develop processes that support hydrothermal flames as the heat source $[36,41]$.

Although the reactor effluent energy can be recovered by a Rankine Cycle, the process is still highly energy demanding. Additionally, oxygen is the most commonly used oxidant in order to reduce the air compressor energy consumption. The implementation of hydrothermal flames as the internal heat source in the supercritical water oxidation processes opens up the opportunity for the SCWO to achieve an energetically selfsufficient process, and to produce energy [51].

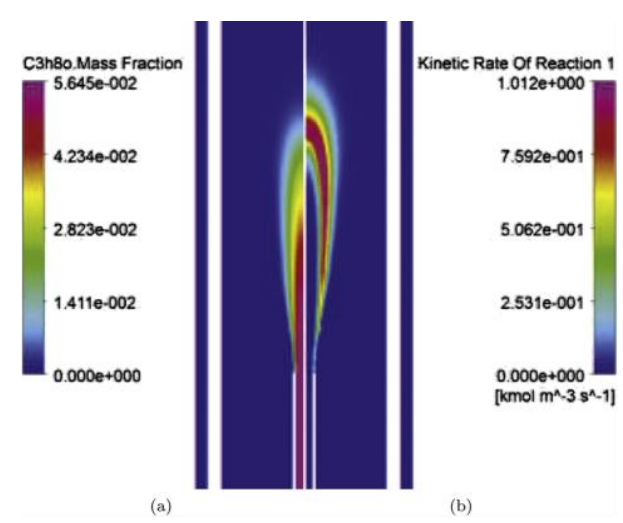

Figure 1. Flame simulation contours of new cooled wall reactor with two outlets: (a) IPA mass fraction, (b) reaction rate [52].

The SCWO processes with hydrothermal flames have a number of advantages over the flameless processes. Some of these advantages could overcome the traditional challenges that make a successful and profitable commercialization of SCWO technology difficult. The advantages include the following [52]:

- The reduced residence times (in the order of milliseconds) encourage the construction of smaller reactors (micro-combustors). 
- It is possible to carry out the reaction with feed injection temperatures near to room temperature when using vessel reactors [48,53]. This avoids problems such as plugging and corrosion in the preheating step, which is an advantage from the perspective of operation and energy integration.

- Higher operation temperatures improve energy recovery.

The extremely low residence time allows micro reactors to be developed as an alternative to the long tubular reactors. The strong reduction of the ignition temperature with pressure will allow the operation at temperatures of $600-650^{\circ} \mathrm{C}$. At those conditions the SCW oxidation achieves a higher efficiency than at lower temperatures. The operation temperature can be even higher if the work recovery required a vapor at a higher temperature.

As the reactor size decreases significantly, the operation with air as the oxidant could be a more economical alternative. On an industrial scale, it could also be possible to implement oxidation with air, as opposed to the conventional SCW facilities that operate with cryogenic oxygen [51].

When direct expansion of the effluent is used, the energetic efficiency is much higher than when the effluent is used to heat an auxiliary fluid of a Rankine or Brayton cycle. We have calculated that it is possible to operate with air as the oxidant, or to use enriched air through the direct expansion of the effluent in a turbine, and thus produce net energy [51-53]. 


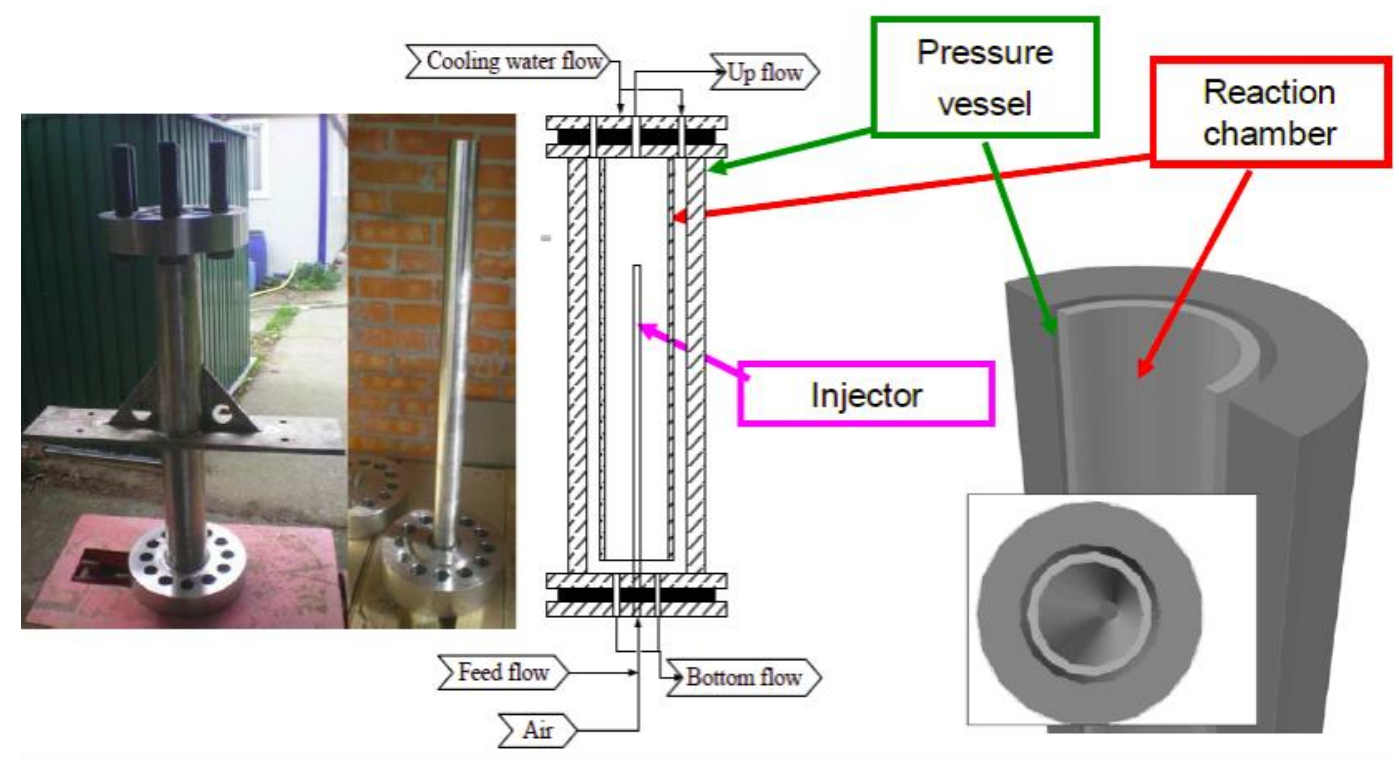

Figure 2. UVa two-outlet reactor for energy production. Details of construction can be found in literature [53].

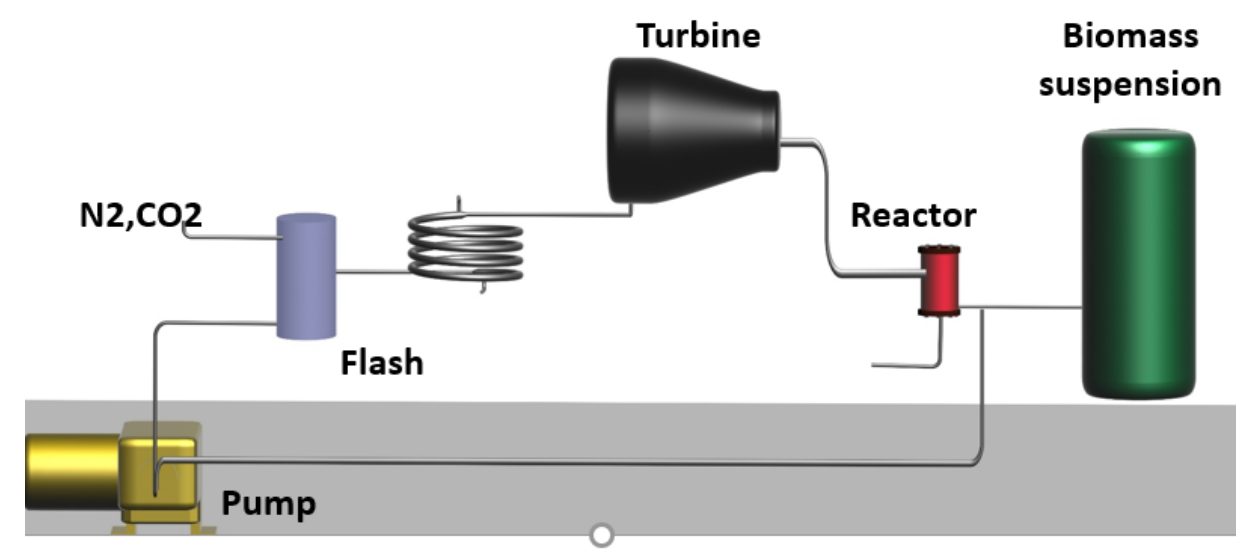

Figure 3. SCWO scheme, designed to operate with a direct effluent reactor expansion in a turbine.

Even when the option of direct expansion of the effluent is, by far, the most energetically efficient, it will be not applicable in the short term. This is mainly due to the fact that the composition of the effluent $(50-80 \%$ mol of water, carbon dioxide and nitrogen if air is used as oxidant) makes it unsuitable for expansion in a conventional turbine. This composition places the effluent somewhere between the pure water used in the steam turbine, and the flue gases, which are products of combustion used in gas 
turbines. The starting conditions of this mixture, at around $600^{\circ} \mathrm{C}$ and $23 \mathrm{MPa}$, determine the near-isentropic path needed for its efficient expansion, and send it down this path to achieve early condensation in order to fully harness the mixture's enthalpy content; depending of course on the exact composition of the mixture. Thus, technical issues concerning the expansion of two-phase streams prevent the effective implementation of direct expansion in the short term. Furthermore, the detailed design of a dedicated, effective turbine would be costly and would take some time to implement [51-54].

The effluent from the SCW oxidation obtained in a short time, with high pressure and temperature, can be expanded in a commercial gas turbine to improve the efficiency of the turbine and integrate the turbine gas effluent to preheat the feed [55].

Biomass could be also an interesting feed material, in order to produce energy by SCWO with a hydrothermal flame as the internal heat source. The study of the conditions to produce a hydrothermal flame from biomass is a challenge, but its development could be an important step to produce in-situ energy for the biorefineries. In addition, technical solutions for injecting biomass in a hydrothermal flame combustor must be developed. For example, continuously pumping highly concentrated biomass suspensions up to supercritical pressures, and its injection into the reactor, is still a challenge [54].

Different wastes, and fuels with high concentrations of inorganics and heteroatoms, which are near unable to be burnt in conventional atmospheric combustion, are fuels which may potentially be used in SCWO for energy production because, with this technology, clean combustion can be obtained. Nevertheless, inorganics solubility is highly reduced in SCW and the inorganics are susceptible to cause plugging problems in the reactor. What is more, the introduction of these inert materials into the reactor cause significant energy inefficiency. 


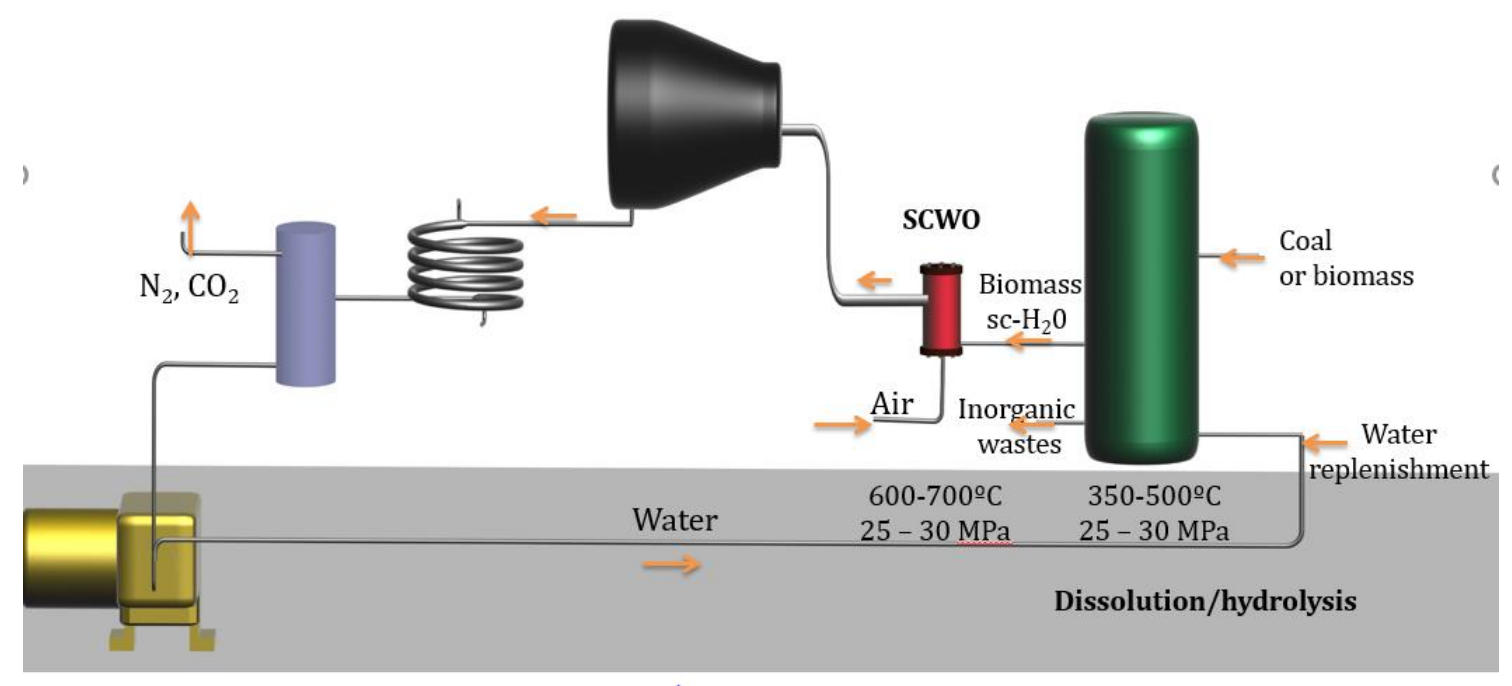

Figure 4. SCWO scheme. Dissolution/hydrolysis pre-treatment to separate inorganic wastes.

Research is needed in order to develop SCW pre-treatment steps that avoid the introduction of these solids into the SCWO reactor. Figure 4 presents a diagram where the SCW is used for dissolution/hydrolysis of the biomass or coal for example, avoiding the dissolution of the inorganic components. The dissolvent material can be oxidized in a micro combustor to render high pressure steam and recover its work in a turbine. The inorganic and non-soluble wastes can be recovered as solids.

The high temperature effluent can also be used as a heat source in other hydrothermal processes, such as liquefaction or gasification, where the amount of energy consumed is a critical issue.

Another process that could be improved by using hydrothermal flames is the hydrothermal flame drilling that may be an alternative to rotary drilling for deep boreholes. The oxidation reaction of hydrothermal flames can be used to rapidly heat a rock surface and induce thermal stresses that lead to the formation of rock fragments, or spalls which are violently ejected from the rock surface and removed from the borehole [36, 41]. 


\subsection{Intensification of the biomass refining processes by using supercritical water hydrolysis: A significant step forward towards a sustainable biorefinery.}

In recent years, many countries have developed strategies focused on giving answers to the challenges that the world is facing [56], such as i) increasing populations that must be fed ii) depletion of natural resources, iii) impacts of ever increasing environmental pressures and iv) climate change. Europe's Bioeconomy Strategy addresses the production of renewable biological resources and their conversion into vital products and bio-energy [57].

In order to overcome these challenges, the research must be focused on achieving the development of environmentally compatible processes, the efficient handling of energy, and reducing the equipment costs. Sustainable processes are characterized by high yield and high selectivity. This is achieved by simplifying the number of process steps, by searching for opportunities among new raw materials or by using clean solvents such as water or carbon dioxide. Reduction in equipment costs involves the development of compact apparatus with short operation times [58].

The use of pressurized fluids has been proposed as an environmentally compatible process for integrating the depolymerization-reaction-separation processes. In particular, high-temperature pressurized water has proved to be a good solvent for clean, safe and environmentally benign organic reactions [59]. Main advantages that make hydrothermal media a promising alternative for biomass processing are: i) it is not necessary to reduce the water content in the raw material, which incurs an important energy saving; ii) the same reaction medium is suitable for the transformation of the different biomass fractions; iii) mass transfer limitations can be reduced, thus reaction rates are faster [60]. The hydrothermal process's main disadvantage is its poor selectivity. It is possible to selectively obtain extracts, oils, proteins, pectin, hemicelluloses or C5 sugars at subcritical conditions, temperatures below $180^{\circ} \mathrm{C}$, but after $200^{\circ} \mathrm{C}$ the degraded products' concentration increases, producing a mixture of 
hydrolyzed products (bio-oil), but the process loses its selectivity to obtain valuable products [61].

Reaction speed - whilst being an advantage to process intensification - is also a significant disadvantage to selectivity when longer reaction times are involved, leading to the degradation of hydrolysis products, resulting in complex reaction mixtures. This degradation and mixture complexity leads to the inefficient recovery of biomass-derived products and intermediates. There is, therefore, a need for greater understanding of the hydrothermal fractionation processes in order to improve process selectivity, which can harness the potential of subcritical and supercritical water fractionation [62].

SCW is an alternative solvent for the dissolution/hydrolysis of biomass. Its low viscosity and high diffusivity facilitate the penetration of water into the complex structure of the lignocellulosic matrix, whilst its low dielectric constant enhances the solubility of organic compounds. Physical properties of water (such as density, ionic product and dielectric constant), can be finely tuned by varying temperature and pressure. At these conditions, the hydrolysis of biomass fractions is rapid (of the order of $20 \mathrm{~ms}$ or less) and the ability to control it presents a means to achieving a significantly more selective biomass fractionation process $[63,64]$.

Whilst poor selectivity is common to both sub- and SCW, there are some significant differences between the reaction media - most notably the difference in the ionic product of water (for example, the $\mathrm{H}^{+} / \mathrm{OH}^{-}$concentration at $300^{\circ} \mathrm{C}$ and $23 \mathrm{MPa}$ is around $2 \cdot 10^{-6} \mathrm{~mol} \cdot \mathrm{L}^{-1}$ vs $2 \cdot 10^{-12}$ at 400 and $25 \mathrm{MPa}$ ) which means that subcritical water has a higher concentration of ions $\left(\left[\mathrm{H}^{+}\right]\right.$and $\left.\left[\mathrm{OH}^{-}\right]\right)$thus favoring ionic reactions rather than the radical reactions that are prevalent under SCW conditions [65].

Studies regarding the hydrolysis of cellulose to oligomers and sugars at extremely low residence times $(0.02 \mathrm{~s})$ presents the fact that oligomer and monomer yield is $98 \%$ $\mathrm{w} \cdot \mathrm{w}^{-1}$, while $5-\mathrm{HMF}$ concentration was lower than $5 \mathrm{ppm}$ at $400^{\circ} \mathrm{C}$ and $23 \mathrm{MPa}$. However, with a residence time of $1 \mathrm{~s}$, cellulose hydrolysis renders $60 \% \mathrm{w} \cdot \mathrm{w}^{-1}$ 
glycolaldehyde at $400^{\circ} \mathrm{C}$ and $23 \mathrm{MPa}$. The residence time was a selectivity factor in the production of sugars or glycolaldehyde. Kinetic and mechanism studies prove that the hydroxide anion concentration in the medium due to water dissociation is the determining factor in the selectivity of the process. The reaction of glucose isomerization to fructose, and its further dehydration to produce 5-hydroxy-methylfurfural, are highly dependent on $\mathrm{OH}^{-}$ion concentration. By increasing $\mathrm{OH}^{-}$, these reactions were minimized, allowing 5-HMF production to be controlled. Under this condition, the retro-aldol condensation pathway was enhanced, instead of the isomerization/dehydration pathway [65].

To take advantage of the properties of both supercritical and subcritical water, improved kinetic and mechanistic models describing the behavior of biomass fractions in the first milliseconds of reaction time is key. It is only through the understanding of the reaction mechanisms and kinetics that selective targeting of specific compounds can be achieved, through limiting the degradation of the hydrolysis products. Limiting reaction times to below 1 second will facilitate the description of these reaction mechanisms and kinetics, as this is the "non-steady state" region of the reaction for most biomass fractions, and thus more of the intermediary products formed through biomass hydrolysis and dissolution can be isolated, characterized and quantified [66].

Achieving this control by limiting residence time has been difficult to achieve because of the technical challenge presented by the rapid heating and cooling requirements. The sudden-expansion micro-reactor developed by our research group is an opportunity to explore these challenges deeply, see figure 5. 


\section{Ultrafast reactor - Sudden expansion reactor}

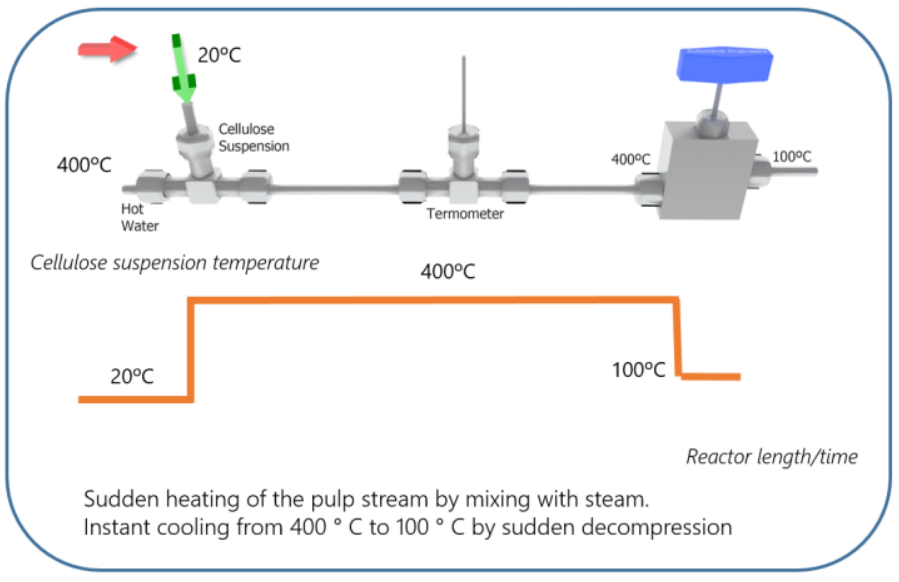

Figure 5. Sudden-expansion micro-reactor, control of the heating and cooling steps [67].

Although proof of principle has been achieved, fundamental understanding regarding exactly how the biomass behaves under these short residence time reactions is still lacking. Improved models of the reaction mechanisms and kinetics that govern the hydrolysis and dissolution of cellulose and lignin under SCW conditions will enable scientists to design reactors and provide conditions specifically tailored towards the fractionation of these biopolymers into discreet fractions of the desired size and/or chemical characteristics.

Other challenges presented by supercritical water hydrolysis are energy consumption, and the dilution of the products in the effluent. After depressurization, a flash divides a highly pressurized vapor and a concentrate effluent. As in the SCWO process, it is possible to expand the pressurized vapor inside a commercial gas turbine in order to improve the efficiency of the turbine. The turbine gas effluent can be used to preheat the water effluent in order to produce the supercritical water. The heat recovery plays an important role in reducing the energy consumption of the process. Good heat integration between a supercritical water hydrolysis process and a gas turbine could achieve an energetically self-sufficient process [68]. Research is also needed in order 
to develop the downstream processes for concentrating/separating the effluent, thus producing the final products.

The SCW hydrolysis of biopolymers, such as cellulose, opens a new route for developing new products that cannot be obtained by the conventional acid or alkaline hydrolysis. Biomass with a high cellulose concentration could be a raw material for producing cellulose with different molecular weight and properties, with new market opportunities.

Although research is needed to improve the fundamental knowledge of biomass SCW hydrolysis, the first SCW hydrolysis process, called the Plantrose process, developed by Renmatix, is running in a demonstration scale in Georgia, USA [69].

\subsection{Supercritical water as a reaction media to produce building blocks}

The SCW can be used as a reaction medium to produce chemical compounds with high selectivity. The selectivity is improved by controlling the ion concentration in order to avoid ionic reactions. This has been presented in the case of cellulose hydrolysis.

The glucose and fructose kinetic and reaction mechanism studies have allowed us to determine reaction paths for obtaining the selection of glycolaldehyde (building block compound made up of two carbons) or pyruvaldehyde (building block compound made of three carbons). The reactions were assumed to follow the reaction pathway shown in figure 6. 


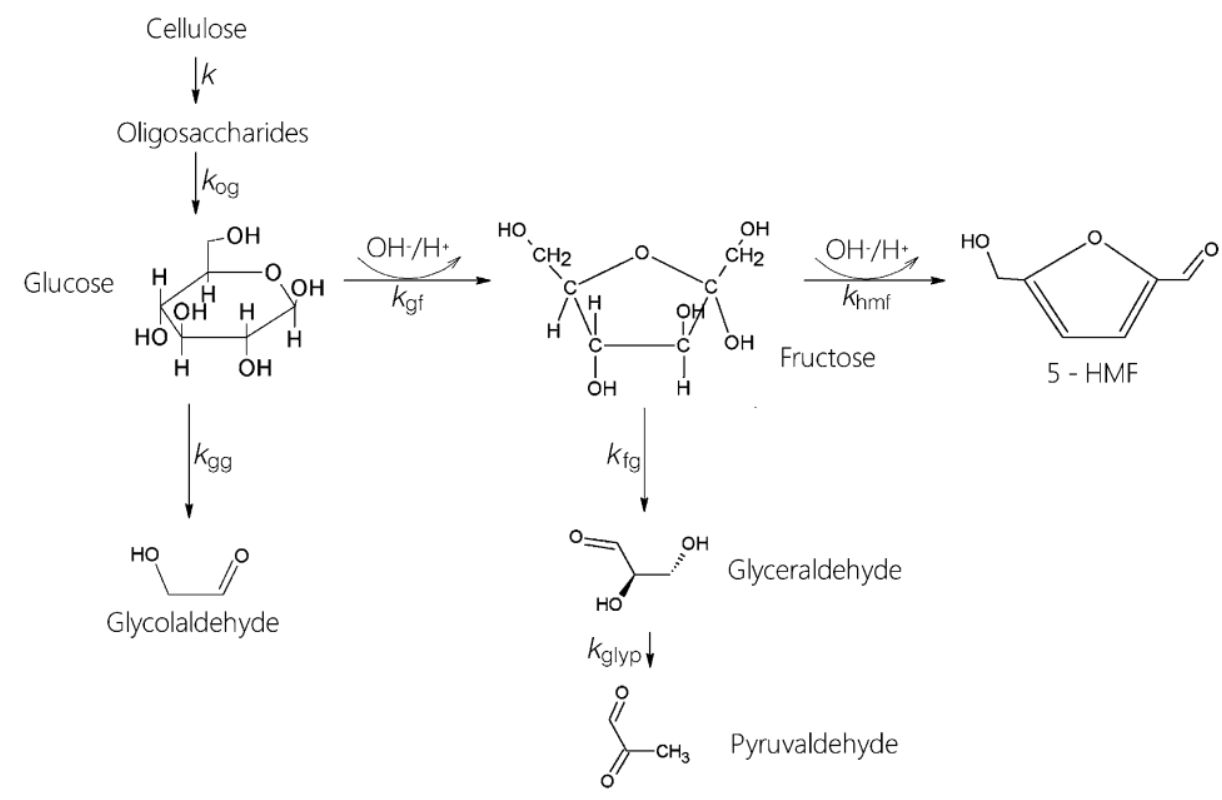

Figure 6. Reaction pathway of glucose and fructose hydrolysis in supercritical water. This reaction pathway was built following the schemes developed in reference [70]. The reaction of glucose isomerization occurs through ring opening and keto-enol tautomerism. These reactions form transition states with $\mathrm{OH}-$ or $\mathrm{H}+$ ions. Also, fructose dehydration forms transition states incorporating $\mathrm{H}_{+}$ions (one per $\mathrm{H}_{2} \mathrm{O}$ molecule lost) [71]. The production of glycolaldehyde was enhanced at supercritical conditions because the $\mathrm{OH}-/ \mathrm{H}+$ concentration is highly decreased and so is the concentration of fructose and its derived products. Fructose can follow two main reaction pathways: fructose dehydration or retroaldol condensation and a second reaction to form glyceraldehyde as the main product from fructose $[65,66]$.

Results show that fructose can be selectively transformed into pyruvaldehyde, at $400^{\circ} \mathrm{C}$ and $23 \mathrm{MPa}$ with a yield of $89 \% \mathrm{w} \cdot \mathrm{w}^{-1}$ without using any catalyst, and with a residence time of $0.7 \mathrm{~s}[72]$.

The hydrolysis of glucose to glycolaldehyde was achieved at $400^{\circ} \mathrm{C}$ and $23 \mathrm{MPa}$ with a residence time of $3 \mathrm{~s}$; glycolaldehyde selectivity at those conditions was $75 \% \mathrm{w} \cdot \mathrm{w}^{-1}$ [73]. The reactions of fructose were analyzed in combination with glucose. It was determined that different retro-aldol condensation products can be obtained depending 
on the starting material. Fructose produces mainly C-3 molecules (pyruvaldehyde) and glucose produces mainly C-2 molecules (glycolaldehyde). The isomerization of fructose to glucose is negligible, and so is the production of C-2 when the starting material is fructose. The non-ionic medium induced at supercritical water conditions significantly improves the selectivity, favoring the retro-aldol condensation of glucose instead of isomerization or dehydration.

Organic chemistry has developed systematic mechanisms to produce many chemical products from oil. These reactions are founded on simple molecules, such as ethene, propene or benzene, with the addition of functional groups. In the oil industry, chemical processes require multiple steps, the use of solvents, catalysts and excessive energy, which have environmental incompatibilities. In the bio-based chemical industry, key compounds are more complicated molecules with highly functional groups, such as glucose for example. Now, a new systematization of organic chemistry for the removal or rearrangement of the functional groups has to be developed. The chemical processes must include simplified steps and improved process intensification in order to achieve a sustainable process from biomass.

\section{Concluding remarks, and identification of the research needed for the development of the intensification of the sustainable supercritical water processes.}

The SCW processes have been devoted to important, marketable research efforts, but it has not been possible to achieve the industrial development that was expected.

Among the reasons for this problem are the high processing cost, and the difficulty of operating with solids at a high pressure and temperature. Taking into account the SCW properties as the reaction media, the SCW process intensification is presented as an alternative for developing an ultrafast process that allows a reduction in the reactor cost. Work recovery, heat integration and heat and shaft work production are considered to minimize energy consumption or even produce net energy. 
The intensification of the SCW oxidation process by using hydrothermal flame as an internal heat source is presented as an alternative for developing micro combustors. The expansion of the effluent in a turbine could be the way to produce in-situ energy for biorefinery development. Our preliminary results concerning the SCW oxidation reactor with the hydrothermal flame as the internal heat source indicated that it would be possible to produce energy by expanding the SCW oxidation reactor effluent in a turbine. To develop this process, some research needs could be summarized as follows:

New studies to develop stable hydrothermal flames from different compounds, mainly biomass from different origins, and to establish the methodology for calculating them.

To improve the reactor's design and reduce the plugging problems, taking into account its operation with solids at a high pressure and temperature, and to develop new construction materials to control the corrosion and reduce the equipment costs.

The work and energy recovery have a key relevance, due to the high temperatures and pressure effluents and the process high energetic consumptions. Therefore it is necessary to develop new turbines that can operate with the SCW oxidation effluents to recover the work.

To study technical issues concerning the expansion of two phase streams in order to implement the direct expansion effluents.

The SCW ultrafast hydrolysis is presented as an alternative for developing sustainable biorefineries. The SCW media properties allow it to operate mainly by ionic reaction mechanisms at subcritical water, and by radical reactions mechanism at SCW. The operation with ultrafast micro reactors has remarkably increased the selectivity. The fundamental knowledge about the reaction mechanism and the effect of SCW properties are a key point in achieving this selectivity. 
This implies that future research about the reaction mechanism must be carried out in continuous reactors in order to obtain accurate data. The heating and cooling steps should be taken into account to avoid degradation, and to control the residence time. The operation with solids at a high pressure and temperature has to be considered in all the process steps.

In the same way, high pressure view-cells used in solubility and phase behavior studies on biomass hydrothermal reaction require that the preheating time be avoided, since the dissolution/hydrolysis step could be extremely fast and thus take place during the preheating. Therefore, continuous flow cells, or those provided with a system for solid injection, will be the most widely used.

The application of the SCW intensified process required commercial equipment to operate continuously with low residence times. In fact, the commercial equipment itself, even a lab scale commercial suspension pump equipped with valves that avoid plugging due to suspension particles, is needed. Technicians with the experience to implement this commercial equipment in the research lab are also needed.

In addition, even when the components of biomass are alike, each biomass presents its own peculiarities. Thus, one must study new local biomass sources to achieve specific chemicals and energy.

Knowledge mechanisms based on SCW hydrolysis, such as the SCW ultrafast hydrolysis, are proposed in order to obtain selective building blocks. Two examples for producing highly selective C2 and C3 building blocks from fructose and glucose are presented as an alternative to the production of selective chemicals by the intensified SCW hydrolysis process.

Research requires organic chemistry to allow the elimination and rearrangement of functional groups from the building blocks produced, whereas chemical engineering enables the development of simplified and compact 
processes, taking into account energy recovery and process integration, contributing as a whole to the development of the Bioeconomy.

\section{Acknowledgements}

The author thanks the Ministerio de Economía y Competitividad, Junta Castilla y León and FEDER program for their financial support of our Bioeconomy Projects CTQ201344143-R, CTQ2016-79777-R, and VA040U16.

\section{References}

[1] A. Anderko, K.S. Pitzer, Equation-of-state representation of phase equilibria and volumetric properties of the system $\mathrm{NaCl}-\mathrm{H}_{2} \mathrm{O}$ above $573 \mathrm{~K}$, Geochimica et Cosmochimica Acta 57 (1993) 1657-1680.

[2] J.F. Connoll, Solubility of Hydrocarbons in Water Near the Critical Solution Temperatures, J Chem Eng Data 11 (1966) 13-16. DOI: 10.1021/je60028a003

[3] T.B. Thomason, M Modell, Supercritical water destruction of aqueous wastes, Hazardous Waste 1(4) (1984) 453-467.

[4] R.W. Shaw, N. Dahmen, Destruction of toxic organic materials using supercritical water, In Supercritical fluids fundamentals and application. E. Kiran Ed 425 Nato ASI. Blackie Academic. 2000.

[5] M.L. Japas, E.U. Franck, High-pressure phase-equilibria and PVT-data of the water-nitrogen system to 673-K and $250 \mathrm{MPa}$, Ber. Bunsen-Ges. Phys. Chem. Chem. Phys. 89 (7) (1985) 793-800.

[6] A.E. Mather, E.U. Franck, Phase-equilibria in the system carbon-dioxide water at elevated pressures, J. Phys. Chem. 96 (1) (1992) 6-8.

[7] E.U. Franck, G. Wiegand, High pressure hydrothermal combustion, Pol. J. Chem. 70 (5) (1996) 527-543.

[8] M.J. Cocero, Supercritical Water Oxidation. Application to Industrial waste water treatment, In High Pressure Process Technology: Fundamentals and Applications. A. Bertuco, G. Vetter Eds. Elsevier 2000.

[9] M.J. Cocero, J.L. Soria, F. Fdz Polanco, Behaviour of a cooled wall reactor for the supercritical water oxidation process, In High Pressure in Chemical Engineering. R. van Rohr, Ch. Trepp Eds. Elsevier 1996.

[10] P.A. Marrone, Supercritical water oxidation - current status of full scale commercial activity for waste destruction, J. Supercrit Fluids 79 (2013) 283-288.

[11] A. Martin, M.D. Bermejo, M.J. Cocero, Recent developments of supercritical water oxidation: A patents review, Recent Patents on Chemical Engineering 4 (2011) 219230.

[12] M.D. Bermejo, M.J. Cocero, Supercritical water oxidation: A technical review, AIChE J. 52 (2006) 3933-3951.

[13] The SuperWater process, 2017. SuperWater Solutions.

http://www.superwatersolutions.com/technology.html. 
[14] Sludge treatment / SCFI - smarter environmental technology, 2017.

Http://www.scfi.eu/products/sludge-treatment-3/

[15] J.W. Griffith, D.H. Raymond, The first commercial supercritical water oxidation sludge processing plant, Waste Management 22 (2002) 453-459.

[16] P. Kritzer, Corrosion in high-temperature and supercritical water and aqueous solutions: a review, J. Supercrit Fluids 29 (2004) 1-29.

[17] P. Kritzer, E. Dinjus, An assessment of supercritical water oxidation (SCWO)existing problems, possible solutions and new reactor concepts, Chem. Eng. J. 83 (3) (2001) 207-214.

[18] F.J. Armellini, G.T. Hong, J.W. Tester, Precipitation of sodium chloride and sodium sulfate in water from sub- to supercritical conditions: $150^{\circ}$ to $550^{\circ}, 100$ to $300 \mathrm{bar}$, J Supercrit Fluids. 7 (1994) 147-158.

[19] M.D. Bermejo, M.J. Cocero, F. Fdz-Polanco, A process for generating power from the oxidation of coal in supercritical water, Fuel. 83 (2004) 195-204.

[20] M.J. Cocero, E. Alonso, M. Sanz, F. Fdz-Polanco, Supercritical water oxidation process under energetically self-sufficient operation, J. Supercritical Fluids 24 (2002) 37-46.

[21] E.D. Lavric, H. Weyten, J. De Ruyck, V. Plessu, V. Lavric, Delocalized organic pollutant destruction through a self-sustaining supercritical water oxidation process, Energy Conversion and Management 46 (2005) 1345-1364.

[22] Hydromethan AG http://www.hydromethan.ch/technologie_en.html

[23] C. Rodríguez-Correa, A. Kruse, Supercritical Water Gasification of Biomass for Hydrogen Production - Review, J. Supercrit Fluids. Biomass fractionation processes by subcritical \& Supercritical water special issue. 2017.

[24] E. Gasafi, M. Reinecke, A. Kruse, L. Schebek, Economic analysis of sewage sludge gasification in supercritical water for hydrogen production, Biomass and Bioenergy 32(12) (2008) 1085-1096. doi:10.1016/j.biombioe.2008.02.021

[25] A. Kruse, Hydrothermal biomass gasification, J. Supercrit Fluid. 47(3) (2009) 391399. doi:10.1016/j.supflu.2008.10.009.

[26] T. Adschiri, Y.-W. Lee, M. Goto, S. Takami, Green materials synthesis with supercritical water (review), Green Chemistry 13 (2011) 1380-139.

[27] Y.H. Shin, S-M Koo, D S Kim, Y-H Lee, B. Veriansyah, J Kim, Y.-W. Lee, Continuous hydrothermal synthesis of $\mathrm{HT}$-LiCoO2 in supercritical water, J. Supercrit Fluids 50 (2009) 250-256.

[28] J. Sierra-Pallares, T. Huddle, E. Alonso, F. Mato, J. García-Serna, M.J. Cocero, E. Lester, Prediction of residence time distributions in supercritical hydrothermal reactors working at low Reynolds numbers, Chemical Engineering J. 299 (2016) 373-385.

[29] Shyman http://cordis.europa.eu/project/rcn/103330 en.html

[30] T. Adschiri, Supercritical fluids for nanotechnology, J. Supercrit Fluids. $30^{\text {th }}$ years special issue.

[31] C. Aymonier, G. Philippot, A. Erriguible, S. Marre, Playing with solvents in supercritical conditions and the associated technologies for advanced materials by design, J Supercrit Fluids $30^{\text {th }}$ Year Special issue.

[32] R.O. Caniaz, C. Erkey, Process intensification for heavy oil upgrading using supercritical water, Chem. Eng. Research \& Design 92 (2014) 1845-1863. 
[33] R.O. Canıaz, S. Şimşek, S. Arca, E. Sarayloo, I. H. Kavakl, C. Erkey, Upgrading blends of sustainable microalgae feed stocks and heavy oils in supercritical water, $J$ Supercrit Fluid. Biomass fractionation processes by subcritical \& supercritical water special issue 2017.

[34] M.T. Timko, A. F. Ghoniem, W. H. Green, Upgrading and desulfurization of heavy oils by supercritical water, J Supercritical Fluid 96 (2015) 114-123.

[35] J. Vilcaez, M. Watanabe, N. Watanabe, A Kishita, T Adschiri, Hydrothermal extractive upgrading of bitumen without coke formation, Fuel 102 (2012) 379-385.

[36] G. Brunner, Hydrothermal and Supercritical water processes, Supercritical Fluids Science and Technology Series. E. kiran Ed. Elsevier 2014.

[37] G. Lu, H. Lu, W. Su, L. Wang, Z. Zhu, Supervision and significance on the core parameters for steam and water system in supercritical utility thermal power plant, Advanced Materials Research 610-613 (2013) 2455-2458.

[38] Y. Su, K.S. Chaudri, W. Tian, G. Su, S. Qiu, Optimization study for thermal efficiency of supercritical water reactor nuclear power plant, Annals of Nuclear Energy. 63 (2014). 541-547. doi:10.1016/j.anucene.2013.08.023

[39] L. Vaquerizo, M.J. Cocero, A green desuperheater for an energetic efficient alternative to the decompression valve in biomass supercritical water ultrafast hydrolysis process, J Supercrit Fluids. Biomass fractionation processes by subcritical \& supercritical water special issue. https://doi.org/10.1016/j.supflu.2017.07.002

[40] W. Schilling, E. Franck, Combustion and diffusion flames at high pressures to 2000 bar, Berichte Der Bunsen-Gesellschaft-Physical Chemistry Chemical Physics 92 (1988) 631-636.

[41] C. Augustine, J. Tester, Hydrothermal flames: From phenomenological experimental demonstrations to quantitative understanding, J. Supercrit Fluids. 47 (2009) 415-430.

[42] J.P.S. Queiroz, M.D. Bermejo, M.J. Cocero. Numerical study of the influence of geometrical and operational parameters in the behavior of a hydrothermal flame in vessel reactors. Chem Eng Science 112 (2014) 47-55.

[43] R.M. Serikawa, T. Usui, T. Nishimura, H. Sato, S. Hamada, H. Sekino, Hydrothermal flames in supercritical water oxidation: investigation in a pilot scale continuous reactor, Fuel. 81 (2002) 1147- 59.

[44] J. Sierra-Pallares, M.T. Parra-Santos, J. Garcia-Serna, F. Castro, M.J. Cocero, Numerical modelling of hydrothermal flames. micromixing effects over turbulent reaction rates, J Supercrit Fluids. 50 (2009) 146-154.

[45] J. Warnatz, U. Maas, R.W. Dibble, Combustion: physical and chemical. fundamentals, modeling and simulation, experiments, pollutant formation. Springer. 2006

[46] M.D. Bermejo, P. Cabeza, M. Bahr, R. Fernández, V. Rios, C. Jimenez, M.J Cocero, Experimental study of hydrothermal flames initiation using different static mixer configurations, J Supercrit Fluids 50 (2009) 240-249.

[47] M.D. Bermejo, C. Jiménez, P. Cabeza, A. Matias-Gago, M.J. Cocero, Experimental study of hydrothermal flames formation using a tubular injector in a refrigerated reaction chamber. Influence of the operational and geometrical parameters, J Supercrit Fluids. 59 (2011)140-148. 
[48] M.D Bermejo, P. Cabeza, J. Queiroz, C. Jimenez, M.J Cocero, Analysis of the scale up of a transpiring wall reactor with a hydrothermal flame as a heat source for the supercritical water oxidation, J. Supercrit Fluids. 56 (2011) 21-32.

[49] B. Wellig, K. Lieball, P. von Rohr, Operating characteristics of a transpiring-wall SCWO reactor with a hydrothermal flame as internal heat source, J Supercrit Fluids. 34 (2005) 35-50

[50] B. Wellig, M. Weber, K. Lieball, K. Prikopsky, P. von Rohr, Hydrothermal methanol diffusion flame as internal heat source in a SCWO reactor, J Supercrit Fluids 49 (2009) 59-70.

[51] P. Cabeza, J.P.S. Queiroz, C. Jiménez, M.D. Bermejo, F. Mato, M.J. Cocero, Supercritical water oxidation for energy production by hydrothermal flame as internal heat source. Experimental results and energetic study, Energy 90 (2015) 1584-1594.

[52] J.P.S. Queiroz. On the Development of Computational Tools for the Modeling and Simulation of SCWO Process intensified by hydrothermal flames. PhD thesis, Universidad de Valladolid. (Spain) 2014.

https://uvadoc.uva.es/bitstream/10324/6499/6/TESIS576-141010.pdf

[53] P. Cabeza, Studies in the development of SCWO vessel reactors with hydrothermal flame as an internal heat source. $\mathrm{PhD}$ thesis. Universidad de Valladolid. (Spain). 2012. https://uvadoc.uva.es/bitstream/10324/2026/1/TESIS248-130131.pdf

[54] M.D. Bermejo, A. Martín, J.P.S. Queiroz, P. Cabeza, F. Mato, M.J. Cocero, Supercritical water oxidation (SCWO) of solid, liquid and gaseous fuels for energy generation, in: Z. Fang, C.C. Xu (Eds.), Near-critical and supercritical water and their applications for biorefineries, number 2 in Biofuels and Biorefineries. Springer Verlag. 2014.

[55] Y. García, F. Mato, A. Martin, M.D. Bermejo, M.J. Cocero, Energy recovery from effluents of supercritical water oxidation reactors, J Supercrit Fluids. 104 (2015) 1-9.

[56] The Spanish Bioeconomy Strategy 2030 Horizon.

http://bioeconomia.agripa.org/download-doc/102159

[57] The European Bioeconomy Strategy.

http://ec.europa.eu/research/bioeconomy/index.cfm?pg=policy\&lib=strategy

[58] K. Arai, R.L. Smith, T.M. Aida, Decentralized chemical processes with supercritical fluid technology for sustainable society, J. Supercrit Fluids 47 (2009) 628-636. https://doi.org/10.1016/j.supflu.2008.11.008

[59] N. Akiya, P.E. Savage, Roles of Water for Chemical Reactions in HighTemperature Water, Chemical Reviews 102 (2002) 2725-2750.

[60] D.A. Cantero, M.D. Bermejo, M.J. Cocero, Reaction engineering for process intensification of supercritical water biomass refining, J. Supercrit Fluids 96 (2015) 2135. doi.org/10.1016/j.supflu.2014.07.003

[61] G. Gallina, Á. Cabeza, P. Biasi, J. García-Serna, Optimal conditions for hemicelluloses extraction from Eucalyptus globulus wood: hydrothermal treatment in a semi-continuous reactor, Fuel Process. Technol. 148 (2016) 350-360.

doi:http://doi.org/10.1016/j.fuproc.2016.03.018. 
[62] M.J. Cocero, Á. Cabeza, N. Abad, T. Adamovic, L. Vaquerizo, C. M. Martínez, M. V. Pazo-Cepeda, Understanding biomass fractionation in subcritical \& supercritical water. J Supercritical Fluids, In press. https://doi.org/10.1016/j.supflu.2017.08.012

[63] T. Adschiri, R M. Malaluan, S. Hirose, K. Arai, Uncatalytic conversion of cellulose in subcritical and supercritical water, J. Chem. Eng. Jpn. 26 (6) (1993) 676-680.

[64] M. Sasaki, Z. Fang, Y. Fukushima, T. Adschiri, K. Arai, Dissolution and hydrolysis of cellulose in subcritical and supercritical water, Ind \& Eng Chem Research. 39(8) (2000) 2883-2890.

[65] D.A. Cantero, M.D. Bermejo, M.J. Cocero, Governing chemistry of cellulose hydrolysis in supercritical water, ChemSusChem. 8 (2015) 1026-1033.

doi:10.1002/cssc.201403385

[66] M. Sasaki, T. Adschiri, K. Arai, Kinetics of cellulose conversion at $25 \mathrm{MPa}$ in suband supercritical water, AIChE J. 50(1) (2004) 192-202.

[67] D.A. Cantero. Intensification of cellulose hydrolysis process by supercritical water. Obtaining of added value products. PhD thesis. Universidad de Valladolid. (Spain). 2014. https://uvadoc.uva.es/bitstream/10324/5374/1/TESIS552-140717.pdf

[68] D.A. Cantero, L. Vaquerizo, F Mato, M.D. Bermejo, F. Mato, M.J. Cocero, Energetic approach of biomass hydrolysis in supercritical water, Bioresource Technology 179 (2015) 136-143.

[69] Renmatix. http://renmatix.com/

[70] M. Sasaki, K. Goto, K. Tajima, T. Adschiri, K. Arai, Rapid and selective retro-aldol condensation of glucose to glycolaldehyde in supercritical water, Green Chem. 4(3) (2002) 285-287.

[71] R S Assary, T Kim, J.J. Low, J Greeley, L A Curtiss, Glucose and fructose to platform chemicals: understanding the thermodynamic landscapes of acid-catalysed reactions using high-level ab initio methods, Physical Chemistry Chemical Physics. 14(48) (2012) 16603-16611.

[72] D.A. Cantero, L. Vaquerizo, C.M. Martinez, M.D. Bermejo, M.J. Cocero, Selective transformation of fructose and high fructose content biomass into lactic acid in supercritical water, Catalysis Today 255 (2015) 80-86.

[73] D.A. Cantero, A. Álvarez, C.M. Martinez, M.D. Bermejo, M.J. Cocero, Transformation of glucose into added value compounds in a hydrothermal reaction media, J Supercrit Fluids. 98 (2015) 204-210. 